\title{
Masticatory Biomechanics of the Laotian Rock Rat, Laonastes aenigmamus, and the Function of the Zygomaticomandibularis Muscle
}

The Laotian rock rat, Laonastes aenigmamus, is one of the most recently discovered species of rodent, and displays a cranial morphology that is highly specialised. The rostrum of $L$. aenigmamus is exceptionally elongate and bears a large attachment site for the infraorbital portion of the zygomaticomandibularis muscle (IOZM), which is particularly well-developed in this species. In this study, we used finite element analysis to investigate the biomechanical performance of the Laotian rock rat cranium and to elucidate the function of the IOZM. A finite element model of the skull of $L$. aenigmamus was constructed and solved for biting on each of the teeth (incisors, premolar and molars). Further load cases were created and solved in which the origin of the IOZM had been moved anteriorly and posteriorly along the rostrum. Finally, a set of load cases were produced in which the IOZM was removed entirely, and its force was redistributed between the remaining masticatory muscles. The analysis showed that, during biting, the most stressed areas of the skull were the zygomatic and orbital regions. Compared to other rodents, L. aenigmamus is highly efficient at incisor gnawing, but less efficient at molar chewing. However, a relatively constant bite force across the molar tooth row may be an adaptation to folivory. Movement of the origin of the IOZM had little on the patterns of von Mises stresses, or the overall stress experienced by the cranium. However, removal of the IOZM had a substantial effect on the total deformation experienced by the skull. In addition, the positioning and presence of the IOZM had large impact on bite force. Moving the IOZM origin to the anterior tip of the rostrum led to a substantially reduced bite force at all teeth. This was hypothesised to be a result of the increasing horizontal component to the pull of this muscle as it is moved anteriorly along the rostrum. Removal of the IOZM also resulted in a reduced bite force, even when the total input muscle force was maintained at the same level. It was thus concluded that the function of the IOZM in $L$. aenigmamus is to increase bite force whilst reducing cranial deformation. If the IOZM can be 
shown to have this function in other rodent groups, this may help explain the evolution of this muscle, and may also provide an understanding of why it has evolved independently several times within rodents. 


\section{Authors: Philip G Cox ${ }^{1}$, Joanna Kirkham ${ }^{2,3}$ and Anthony Herrel ${ }^{4}$}

${ }^{1}$ Centre for Anatomical and Human Sciences, Hull York Medical School, University of Hull, Hull, $U K$

${ }^{2}$ Centre for Anatomical and Human Sciences, Hull York Medical School, University of York, York, $U K$

${ }^{3}$ College of Medical and Dental Sciences, University of Birmingham, Birmingham, UK ${ }^{4} U M R$ CNRS/MNHN 7179, Mécanismes adaptatifs: des organismes aux communautés, Paris, France

\section{Corresponding author: Philip G. Cox}

Address: Centre for Anatomical and Human Sciences, Hull York Medical School, University of Hull, Cottingham Road, Hull, HU6 7RX, UK

Telephone: 01904321744

Email: philip.cox@hyms.ac.uk

\section{Introduction}

3 The Rodentia is the most speciose of all mammalian orders, with over 2,200 extant species 4 (Wilson \& Reeder, 2005) in addition to a large number of fossil forms. Despite such taxonomic 5 diversity, morphological variation within the order is relatively limited, particularly with regard 6 to the skull and mandible (Wood, 1965; Hautier et al., 2011). Hence, determining relationships 7 between rodent species based on morphology is difficult, and rodent taxonomy has been 8 historically controversial, with two competing classifications arising in the second half of the $19^{\text {th }}$ 9 century. First, Brandt (1855) split the rodents into three suborders (Sciuromorpha, 10 Hystricomorpha and Myomorpha) based on the morphology of the masseter muscle and its 11 attachment to the rostrum (see Cox \& Jeffery, 2011 for details). Later, Tullberg (1899) divided the 12 rodents into two groups (Sciurognathi and Hystricognathi) based on the position of the angular 13 process of the mandible relative to the incisor. Recent molecular phylogenies (Blanga-Kanfi et 14 al., 2009; Churakov et al., 2010; Fabre et al., 2012) have shown that neither of these 15 classifications accurately resolves the evolutionary relationships between the rodents. The three 16 suborders of Brandt (1855), also used by Simpson (1945), have now been discarded, as they are 17 thought to represent polyphyletic groupings of rodents, although the names have been retained in 18 their adjectival form (sciuromorphous, etc) to describe the three morphotypes of the skull and 
19

20

21

22

23

24

masseter (Wood, 1965; Cox \& Jeffery, 2011). The classification of Tullberg (1899) has fared slightly better, with the Hystricognathi still recognised as a monophyletic clade (the Sciurognathi is paraphyletic with respect to the Hystricognathi). However, recent work (Hautier et al., 2011) has questioned the usefulness of sciurognathy and hystricognathy as morphological terms, noting that there exists a continuum of mandibular forms rather than two discrete morphologies, and that some members of the Hystricognathi actually have mandibles that appear to be almost sciurognathous in form.

The Laotian rock rat, Laonastes aenigmamus (Jenkins et al., 2005), is a recently discovered species of rodent from south-east Asia. It shows an unusual mixture of cranial, mandibular and muscular morphologies, combining a large part of the zygomaticomandibularis muscle that extends through the enlarged infraorbital foramen to attach to the rostrum (Hautier \& Saksiri, 2009) with a weak lateral displacement of the angular process of the mandible (Hautier et al., 2011). Thus, the Laotian rock rat brings together a hystricomorphous skull and masseter with a lower jaw that is intermediate between sciurognathous and hystricognathous. This combination of characters has made its phylogenetic relationships difficult to ascertain. When first described, a new family, the Laonastidae, was created to house L. aenigmamus (Jenkins et al., 2005). This family was placed within the Hystricognathi as the sister-group to African mole-rats (Bathyergidae) or the dassie rat (Petromuridae). A subsequent analysis (Dawson et al., 2006) showed that L. aenigmamus was in fact a member of the Diatomyidae, a family of rodents previously thought to have gone extinct in the Miocene. Further work then showed the Laotian rock rat to be the sister-taxon to the Ctenodactylidae (Huchon et al., 2007), a family of rodents that also display the combination of a hystricomorphous skull with a sciurognathous mandible (Hautier, 2010). The Ctenodactylidae and Diatomyidae together form the sister-group the Hystricognathi, within the more inclusive clade Ctenohystrica (Fabre et al., 2012).

One particularly notable characteristic of the Laotian rock rat is the morphology of the zygomaticomandibularis muscle. This muscle is the innermost layer of the masseter, and in the hystricomorph condition extends anteriorly through the orbit and the grossly enlarged infraorbital foramen to take an attachment on the rostrum (Wood, 1965; Cox \& Jeffery, 2011). In $L$. aenigmamus, the infraorbital portion of the zygomaticomandibularis (IOZM) is especially welldeveloped, extending over halfway along the rostrum (Hautier \& Saksiri, 2009), which is itself exceptionally elongated compared to other rodents (Herrel et al., 2012). Various functions have 
been proposed for the IOZM. Becht (1953) noted that its origin on the rostrum between the incisors and cheek teeth would enable it to function as a second class lever during chewing at the molars, but as a third class lever during gnawing at the incisors. Thus, it can produce both fine control at the incisors and strong pressure at the molars. Using electromyography, Weijs \& Dantuma (1975) found that the IOZM was firing at low intensities during jaw opening in rats, and suggested that it may have a role in the fine control of the opening phase of mastication. With regard to L. aenigmamus specifically, Herrel et al. (2012) proposed that the strong development of the IOZM and its anterior origin on the rostrum would produce a strong horizontal force component to the bite. This would result in optimal functioning at low gape angles and the generation of uniform force along the tooth row, both of which would be beneficial for a folivorous diet, which has been suggested for the Laotian rock rat (Scopin et al., 2011).

The aim of this study is to investigate the biomechanics of feeding in Laonastes aenigmamus. Finite element analysis (FEA) will be used to examine the response of the cranium during gnawing at the incisors and chewing at the molars. FEA is a computer-based engineering technique that enables the prediction of stress, strain and deformation in a complex geometric object subjected to a load (Rayfield, 2007). It has been successfully used to study the biomechanics of feeding in a number of mammalian groups (e.g. Dumont, Piccirillo \& Grosse, 2005; Kupczik et al., 2007; Wroe, 2010; Bright \& Rayfield, 2011) including rodents (Cox et al., 2011, 2012). The major advantage of FEA in the study of biological systems is that elements such as muscle or bone can be modified or removed at will, without the practical and ethical concerns that would arise with in vivo work. In this study, the contribution of the IOZM to feeding will be investigated by changing its attachment site and removing it altogether. In this way, we aim to understand the function of the IOZM, which is so highly developed in the Laotian rock rat, and to elucidate why such an unusual morphology has evolved in this species.

\section{Materials \& Methods}

\section{Sample and model creation}

MicroCT scans of an adult female Laonastes aenigmamus (specimen number KY213), previously obtained for an earlier research project (Herrel et al., 2012), were provided by AH. Voxels were isometric and the voxel resolution was $0.137 \mathrm{~mm}$. Further details of the scanning protocol can be found in Herrel et al. (2012). 
Avizo 7.0 (Visualization Sciences Group, Burlington, MA, USA) was used to create a 3D volume reconstruction of the cranium of the Laotian rock rat. The bone and teeth were segmented separately so that different elastic properties could be assigned to them. Within the incisors, the enamel, dentine and pulp were not differentiated, as the scan resolution was not sufficient to distinguish these materials from one another. In addition, varying the material properties of these components has been shown to make little difference to the overall deformation of the skull (Cox et al., 2011). For similar reasons, the periodontal ligament was not included (Wood et al., 2011). The model was converted to an eight-noded FE mesh by direct voxel conversion, using VOX-FE, custom-built FE software (Liu et al., 2012), resulting in a model of 1734787 elements.

\section{Material properties, constraints and loads}

Bone was assigned a Young's modulus of $17 \mathrm{GPa}$, and the teeth were given a Young's modulus of $30 \mathrm{GPa}$. Both materials were modelled to be linearly elastic and isotropic with a Poisson's ratio of 0.3. These values were based on previous nano-indentation work on rodents (Cox et al., 2012) and FE studies on other mammals (Kupczik et al., 2012).

The model was constrained at three locations: the left and right temporo-mandibular joints (TMJ) and the biting tooth. The TMJs were constrained on the ventral surface of the zygomatic process of the squamosal in all three dimensions. However, the biting tooth was only constrained in the dorsoventral axis (i.e. perpendicular to the occlusal plane). The number of nodes constrained at each location varied between 191 and 221.

Loads were added to the model to represent the forces generated by the following muscles: superficial masseter; deep masseter; zygomaticomandibularis (anterior, posterior and infraorbital parts); temporalis (main, orbital and posterior parts); internal pterygoid; and external pterygoid. Muscle attachment sites and directions of pull were assigned based on the detailed dissections presented in Hautier \& Saksiri (2009) and are shown in Figure 1. Table 1 gives the muscle mass and mean fibre length of each masticatory muscle, measured from the dissection of specimen KY213. Muscle masses were converted to volumes, assuming a muscle density of $1.0564 \mathrm{gcm}^{-3}$ (Murphy \& Beardsley, 1974), and the physiological cross-sectional area (PCSA) of each muscle (given in Table 1) was calculated by dividing the muscle volume by mean fibre length. Muscle forces (Table 2) were calculated by multiplying PCSAs by an intrinsic muscle stress value of 0.3 $\mathrm{Nmm}^{-2}$ (van Spronsen et al., 1989). In order to investigate the function of the IOZM, alternate 
110

111

112

113

114

115

116

117

118

119

120

121

122

123

124

125

126

127

128

129

130

131

132

133

134

135

136

137

138

139

140

versions of the models were created with the origin of this muscle moved anteriorly and posteriorly, and also with the IOZM omitted completely on each side. In the models with a posteriorly shifted IOZM, the insertion point of the IOZM was kept the same, resulting in a more vertically directed muscle vector. However, in the models with an anteriorly shifted IOZM, the insertion point was moved to reflect the wrapping of the muscle around the zygomatic process of the maxilla, resulting in a highly horizontally directed muscle vector (see Fig. 1). To facilitate comparisons between models with and without the IOZM whilst retaining the same overall input muscle load, where it was omitted, the force of the IOZM was redistributed across the remaining masticatory muscles. This was done in such a way as to preserve their relative proportions. The muscle forces applied in the absence of the IOZM are given in Table 2.

\section{Model solution and analysis}

The finite element model of Laonastes aenigmamus was solved for biting at each tooth along the dental arcade, using VOX-FE. Gnawing was assumed always to be bilateral, as a result of the close apposition of the incisors, whereas chewing at the premolars and molars was modelled unilaterally on the left side. Von Mises stress patterns across the skull and bite forces at the teeth were recorded from the solved models. Following Cox et al. (2011) and O’Higgins et al. (2011), geometric morphometrics was used to study the deformation patterns across the cranium. Thus, a set of landmarks (3D co-ordinate data) was recorded from each loaded skull, as well as from the original unsolved model. The landmark set was partially based on that in Cox et al. (2011) and is shown in Figure 2. Landmarks were concentrated in the rostral, orbital and zygomatic regions, as these were the areas experiencing the highest strains. The landmarks were then subjected to a geometric morphometric analysis using MorphoJ software (Klingenberg, 2011). This consisted of co-registering the landmarks via Procrustes superimposition followed by a principal components analysis (PCA). Cranial deformations along PC axes were visualised using the EVAN toolbox (http://www.evan-society.org).

The results generated by the Laotian rock rat model were compared to those found in other rodents, such as squirrels, guinea pigs and rats (Cox et al., 2012). As it difficult to compare absolute bite force between models of different sizes, the mechanical efficiency of biting was calculated. Mechanical efficiency of biting is the ratio of output bite force to input muscle force, and represents the proportion of muscle force that is translated into bite force i.e. is not lost to deformation of the mandible or generation of joint reaction force at the condyles (Dumont et al., 
141 2011). As it is a proportion, mechanical efficiency is size-independent and facilitates clearer

142 comparisons between skulls of varying sizes.

\section{Results}

144 Figure 3 shows the von Mises stress patterns generated across the skull of L. aenigmamus during 145 biting at the incisor, first molar and third molar. It can be seen that, aside from the biting tooth, 146 the zygomatic arch is the most stressed region of the skull, followed by the orbital region. The 147 rostrum experiences a moderate degree of stress during incisor gnawing, but is unstressed during 148 molar chewing, and the occipital region is unstressed during all bites. From visual inspection of 149 the stress distribution figures it is difficult to determine a great deal of variation between bites at different points along the tooth row, even between incisors and molars. However, by studying the mean von Mises stresses across the skull (Table 3) it can be seen that there are indeed subtle differences between bites on different teeth. In general, overall stress increases as the bite point moves closer to the jaw articulation from the premolar to the third molar. However, the incisor bite does not fit this trend, and shows the greatest mean stress across the skull of all bites, presumably because the rostrum is stressed in incisor bites but not in molar bites.

156

157

158

159

160

161

162

163

164

165

166

167

168

169

170

The maximum bite force predicted at each tooth is given in Table 4. As would be expected from simple lever mechanics, bite force increases the closer the bite point (the biting tooth) is to the fulcrum (the TMJ). By dividing the bite forces by total input muscle force, the mechanical efficiency of biting has been calculated and can be compared with previous analyses on other rodents (Cox et al., 2012). It can be seen (Figure 4) that the Laotian rock rat performs well at the incisors and premolars, outcompeting the squirrel and guinea pig, and even matching the rat for efficiency at the incisors. However, compared to the other rodents, the mechanical efficiency tails off towards the distal molars and at the third molar, L. aenigmamus has the least efficient bite.

The impact of the IOZM muscle was investigated by altering the position of its origin on the rostrum in VOX-FE. Figure 3 shows the von Mises stress patterns generated across the skull in models with the origin of the IOZM moved anteriorly and posteriorly, as well as in its original position. Despite quite large changes in muscle origins, very few differences can be seen between the models. This situation is confirmed by examining the mean von Mises stresses across the skull (Table 3). It can be seen that moving the IOZM origin anteriorly or posteriorly results in very little change (less than 6\%) in mean von Mises stress during both incisor gnawing and molar 
171 biting. Although not presented here, the same lack of difference was found on examination of the

172 principal strains across the skull. Predicted bite force was also affected very little by moving the

173 IOZM origin caudally to the most posterior part of the rostrum. However, Table 4 shows that an

174 anterior shift of the IOZM origin resulted in quite a substantial reduction in bite force (between

17510 and $13 \%)$.

176 The effect of removing the IOZM muscle (and redistributing its force between the remaining 177 masticatory muscles) can be seen in Figure 3. As when the IOZM origin was moved, few 178 differences could be detected between the von Mises stress patterns by visual inspection alone, 179 and again, this assertion is supported by examination of the mean von Mises stresses across the 180 skull (Table 3). However, it can be seen from Table 4 that the action of the IOZM has a noticeable 181 effect on bite force. It is clear that the presence of the IOZM enables L. aenigmamus to generate a 182 greater bite force than if it were absent, even when the total input muscle force is the same. The 183 reduction in bite force resulting from removal of the IOZM is approximately 10\% for bites on 184 both incisors and molars, which is similar to the effect of shifting the origin of this muscle to the 185 anterior part of the rostrum.

186 In order to analyse the subtle differences between the deformation patterns generated by the 187 various load cases described above, a geometric morphometric analysis was performed. 188 Landmark data from the original solved models, the models with the IOZM moved anteriorly and 189 posteriorly, and models with the IOZM removed and its force redistributed, as well as landmarks 190 from the unsolved model, were all subjected to Procrustes superimposition and PCA. The plot of 191 the first two principal components (together comprising over 98\% of the variation; PC1, 63.2\%; 192 PC2, 35.1\%) is shown in Figure 5. The first principal component largely separates the unloaded 193 model from the solved load cases. The point representing the unloaded model (star symbol) is on 194 the far left of the plot whilst the points representing the loaded models are spread out down the 195 right hand side of the diagram. The warped reconstructions indicate that the difference in 196 deformation between the loaded and unloaded models is largely concentrated in the zygomatic 197 region (also shown in Fig. 3). The incisor bites (squares) are clearly separated from bites on the 198 other teeth on PC2. The cheek teeth bites are more closely grouped together, but separable into 199 bites on each of the different teeth and positioned in order along the second principal component 200 from the premolar (diamonds) to the third molar (lines). It can be seen from the reconstructions at 201 the extremes of PC2 that incisor bites tend to deflect the rostrum dorsally (relative to the orbito- 
202 temporal region), but that molar bites lead to a dorsal movement of the orbital region (relative to

203 the rostrum). Within bites on each tooth, the models with the IOZM origin in its original position

204 (blue symbols), moved anteriorly (green symbols) and moved posteriorly (red symbols) all group 205 together closely at a similar distance from the unloaded model. This demonstrates that a similar 206 amount of deformation is occurring in each of these load cases. However, the symbols 207 representing the models with the IOZM muscle force redistributed between the other masticatory 208 muscles (orange symbols), are positioned further from the unloaded model than the other load 209 cases, indicating that even more deformation is occurring in these models. As the displacement of 210 these symbols is along PC1, it can be seen that the redistribution of the IOZM is leading to 211 greater deformation mainly in the zygomatic region.

\section{Discussion}

213 A finite element model of the skull of the Laotian rock rat, Laonastes aenigmamus, was created, 214 loaded, constrained and solved. It was shown that the area of the skull experiencing the highest 215 levels of stress was the zygomatic arch, including the zygomatic processes of the maxillary and 216 frontal bones, which is likely to be a result of the large amount of masticatory musculature that 217 attaches directly to this area. Similarly high zygomatic stresses have been noted in other rodents 218 (Cox et al., 2012) as well as in other mammalian groups (Dumont, Piccirillo \& Grosse, 2005; 219 Bright \& Rayfield, 2011; Dumont et al., 2011). It has been suggested that, in primates, the 220 downward pull of the masseter muscle on the zygomatic arch may be counterbalanced to some 221 degree by the upward pull of a soft tissue structure, namely the temporal fascia (Curtis et al., 222 2011). Despite many careful dissections (e.g. Baverstock, Jeffery \& Cobb, 2013), no temporal 223 fascia has been found in rodents, and this is also true of L. aenigmamus (Hautier \& Saksiri, 224 2009). Thus, for the time being, it must be assumed that, although the zygomatic stresses are high 225 in L. aegnimamus, they are not so high as to pose a danger of bone fracture.

226 The bite forces predicted in this study demonstrate that the skull of L. aenigmamus can generate 227 bites of $29 \mathrm{~N}$ during gnawing and between 53 and $74 \mathrm{~N}$ during chewing. By dividing these values 228 by the total input muscle force, the mechanical efficiency of biting was calculated. It was shown 229 that the Laotian rock rat is particularly efficient at incisor biting, having a mechanical efficiency 230 greater than squirrels or guinea pigs, and similar to that of rats (Cox et al., 2012), but is less 231 efficient at molar bites compared to these three rodent species. This would seem to indicate that 232 L. aenigmamus is well-adapted for gnawing and less so for chewing, a conclusion that at first 
233 glance appears somewhat at odds with the suggested diet of this species, which is thought to be

234 largely folivorous (Scopin et al., 2011). However, Onoda et al. (2011) have proposed that the

235 generation of a uniform bite force across the tooth row may be beneficial in the processing of 236 fibrous plant material such as leaves. Viewed in this light, L. aenigmamus is well-adapted to 237 folivory with a difference of just $20 \mathrm{~N}$ between its premolar and M3 bites, compared to 30-35 N 238 in squirrels and guinea pigs.

239 One of the more intriguing results of this study is that the position of the IOZM muscle has little 240 effect on the overall stress experienced by the skull of L. aenigmamus. It can be seen from both 241 Figure 3 and Table 3 that neither the pattern of von Mises stresses nor the mean stress across the 242 skull are greatly affected by moving the origin of the IOZM forwards or backwards. This is may 243 be because the IOZM is contributing a relatively small proportion of the total muscle force 244 (around 8\%). Although the IOZM appears quite a large muscle in lateral view (see Hautier \& 245 Saksiri, 2009), it is relatively small compared to the superficial and deep masseters. Moreover, it 246 also possesses the longest muscle fibres of all masticatory muscles, and so its PCSA (and hence 247 muscle force) is comparatively reduced (Table 1). Thus, its ability to impact the overall stress 248 patterns across the skull may be fairly limited and, furthermore, these patterns may be more 249 strongly influenced by skull morphology than by muscle geometry.

250 In contrast to the position of its attachment, the presence or absence of the IOZM has a much 251 stronger effect on the cranial biomechanics of L. aenigmamus. Figure 5 shows that the symbols 252 representing the models without the IOZM are positioned further from the unloaded model that 253 the other load cases, indicating that the removal of the IOZM leads to greater deformation (and 254 therefore strain) across the skull. Thus, one of the major functions of the IOZM, at least in $L$. 255 aenigmamus, appears to be to minimise strain during feeding. This conclusion holds true at all 256 bites, both gnawing and chewing.

257 In addition to its effect on cranial deformation, it was also found that the IOZM has a strong 258 impact on the bite force produced by L. aenigmamus (Table 4). Specifically, removing the IOZM 259 altogether (and redistributing its force between the remaining masticatory muscles) reduces the 260 bite force generated at all teeth. Similarly, moving the origin of the IOZM to the anterior tip of 261 the rostrum reduces bite force to a similar degree. It is likely that this effect is a result of the 262 wrapping of the IOZM around the zygomatic process of the maxilla, which means that as the 
263 IOZM is moved forward, its vector of pull becomes more horizontal (Fig.1), and so less able to 264 generate bite force. On the other hand, moving the origin of the IOZM posteriorly appears to 265 have little effect on bite force. Interestingly, the reduction in bite force resulting from the anterior movement or removal of the IOZM is largely constant along the tooth row - around $10 \%$.

267 Therefore, it would seem that the extension of the zygomaticomandibularis on to the rostrum 268 evolved in order to increase bite force (as proposed by Becht, 1953). Given that there is minimal difference in bite force between the models with the IOZM in its original position and those with the origin moved posteriorly, the position of the IOZM origin halfway along the rostrum may simply have coevolved with the lengthening of the rostrum in this species. Alternatively, Herrel et al. (2012) have suggested that the anterior insertion of the IOZM in L. aenigmamus increases the horizontal component of biting, which leads to anterior displacement of the mandible during jaw closing, which may be advantageous for the processing of leaves. Whatever the driving force behind the anterior extension of the IOZM, the results here indicate that the reason that the IOZM does not extend any further along the rostrum, as is seen in some other hystricomorph rodents such as the springhare (Offermans \& De Vree, 1989) and capybara (Müller, 1933), is because this would lead to a reduction in bite force at both the incisors and cheek teeth (Table 4).

The results of this study have provided some important insights into the role of the IOZM muscle in the feeding behaviour of L. aenigmamus. Further investigations into other rodents, particularly other hystricomorphs, will enable us to understand whether the ability of the IOZM to increase bite force is unique to L. aenigmamus or common to all rodents that possess it. If the latter scenario is true, this could provide a selective advantage that may have driven the evolution of the IOZM, and could explain why it has evolved independently in several rodent groups (Ctenohystrica, Dipodidae, Anomaluroidea and Gliridae). However, finite element models can only shed light on static loading, and therefore cannot inform about the dynamic processes to which the IOZM may contribute, such as propalineal (antero-posterior) movements of the lower jaw, jaw opening or the fine control of gnawing. These activities can be addressed with dynamic modelling techniques, such as multibody dynamics analysis (e.g. Jones et al., 2012), and may well provide a fruitful avenue of research in the future.

\section{Acknowledgements}

292 We thank Jean-Pierre Hugot for providing access to the specimens and Dominique Adriaens, 293 Loes Brabant and Luc Van Hoorebeke for scanning the specimens at the University of Ghent CT 
294 facility (UGCT). We are grateful to Paul O'Higgins and Michael Fagan for access to VOX-FE 295 finite element software. Thanks are due to Laura Fitton for help with model construction, Peter 296 Bazira for technical support with high-performance computing, and Andrew McIntosh and 297 Thomas Püschel for assistance with GMM software.

298 References

299 Baverstock H, Jeffery NS, Cobb SN. 2013. The morphology of the mouse masticatory 300 musculature. Journal of Anatomy 223, 46-60.

301 Becht G. 1953. Comparative biologic-anatomical researcher on mastication in some mammals. 302 Proceedings of the Koninklijke Nederlandse Akademie van Wetenschappen. Series C 56, 508-526.

Blanga-Kanfi S, Miranda H, Penn O, Pupko T, DeBry RW, Huchon D. 2009. Rodent phylogeny revised: analysis of six nuclear genes from all major rodent clades. $B M C$ Evolutionary Biology 9, 71.

Brandt JF. 1855. Beiträge zur nähern Kenntniss der Säugethiere Russlands. Mémoires de l'Academie Imperiale des Sciences de St Pétersbourg, Sixième Série 9, 1-375.

Bright JA, Rayfield EJ. 2011. Sensitivity and ex vivo validation of finite element models of the domestic pig cranium. Journal of Anatomy 219, 456-471.

Churakov G, Sadasivuni M, Rosebloom K, Huchon D, Brosius J, Schmitz J. 2010. Rodent evolution: back to the root. Molecular Biology and Evolution 27, 1315-1327.

Cox PG, Jeffery N. 2011. Reviewing the jaw-closing musculature in squirrels, rats and guinea pigs with contrast-enhanced microCT. Anatomical Record 294, 915-928.

Cox PG, Fagan MJ, Rayfield EJ, Jeffery N. 2011. Finite element modelling of squirrel, guinea pig and rat skulls: using geometric morphometrics to assess sensitivity. Journal of Anatomy 219, 696-709.

Cox PG, Rayfield EJ, Fagan MJ, Herrel A, Pataky TC, Jeffery N. 2012. Functional evolution of the feeding system in rodents. PLoS ONE 7(4), e36299.

Curtis N, Witzel U, Fitton L, O'Higgins P, Fagan M. 2011. The mechanical significance of the temporal fasciae in Macaca fascicularis: an investigation using finite element analysis. Anatomical Record 294, 1178-1190.

Dawson MR, Marivaux L, Li C, Beard KC, Métais G. 2006. Laonastes aenigmamus and the 'Lazarus effect' in recent mammals. Science 311, 1456-1458. 
Dumont ER, Piccirillo J, Grosse IR. 2005. Finite-element analysis of biting behaviour and bone stress in the facial skeletons of bats. Anatomical Record Part A 283, 319-330.

Dumont ER, Davis JL, Grosse IR, Burrows AM. 2011. Finite element analysis of performance in the skulls of marmosets and tamarins. Journal of Anatomy 218, 151-162.

Fabre P-H, Hautier L, Dimitrov D, Douzery EJP. 2012. A glimpse on the pattern of rodent diversification: a phylogenetic approach. BMC Evolutionary Biology 12, 88.

Hautier L. 2010. Masticatory muscle architecture in the gundi, Ctenodactylus vali (Mammalia: Rodentia) Mammalia 74, 153-162.

Hautier L, Saksiri S. 2009. Masticatory muscle architecture in the Laotian rock rat Laonastes aenigmamus (Mammalia, Rodentia): new insights into the evolution of hystricognathy. Journal of Anatomy 215, 401-410.

\section{Hautier L, Rebrun R, Saksiri S, Michaux J, Vianey-Liaud M, Marivaux L. 2011.} Hystricognathy vs sciurognathy in the rodent jaw: a new morphometric assessment of hystricognathy applied to the living fossil Laonastes (Diatomyidae). PLoS ONE 6(4), e18698.

Herrel A, Fabre A-C, Hugot J-P, Keovichit K, Adriaens D, Brabant L, Van Hoorebeke L, Cornette R. 2012. Ontogeny of the cranial system in Laonastes aenigmamus. Journal of Anatomy 221, 128-137.

\section{Huchon D, Chevret P, Jordan U, Kilpatrick CW, Ranwez V, Jenkins PD, Brosius J, Schmitz} J. 2007. Multiple molecular evidences for a living mammalian fossil. Proceedings of the National Academy of Sciences USA 104, 7495-7499.

Jenkins PD, Kilpatrick CW, Robinson MF, Timmins RJ. 2005. Morphological and molecular investigations of a new family, genus and species of rodent (Mammalia: Rodentia: Hystricognatha) from Lao PDR. Systematics and Biodiversity 2, 419-454.

Jones MEH, O'Higgins P, Fagan MJ, Evans SE, Curtis N. 2012. Shearing mechanics and the influence of a flexible symphysis during oral food processing in Sphenodon (Lepidosauria: Rhynchocephalia). Anatomical Record 295, 1075-1091.

Klingenberg CP. 2011. MorphoJ: an integrated software package for geometric morphometrics. Molecular Ecology Resources 11, 353-357.

Kupczik K, Dobson CA, Fagan MJ, Crompton RH, Oxnard CE, O'Higgins P. 2007. Assessing mechanical function of the zygomatic region in macaques: validation and sensitivity testing of finite element models. Journal of Anatomy 210, 41-53. 
Liu J, Shi L, Fitton LC, Phillips R, O’Higgins P, Fagan MJ. 2012. The application of muscle wrapping to voxel-based finite element models of skeletal structures. Biomechanics and Modeling in Mechanobiology 11, 35-47.

Müller A. 1933. Die Kaumuskulatur des Hydrochoerus capybara und ihre Bedeutung für die Formgestaltung des Schädels. Morphologisches Jahrbuch 72, 1-59.

Murphy RA, Beardsley AC. 1974. Mechanical properties of the cat soleus muscle in situ. American Journal of Physiology 227, 1008-1013.

Offermans M, De Vree F. 1989. Morphology of the masticatory apparatus in the springhare, Pedetes capensis. Journal of Mammalogy 70, 701-711.

O’Higgins P, Cobb SN, Fitton LC, Groning F, Phillips R, Liu J, Fagan MJ. 2011. Combining geometric morphometrics and functional simulation: an emerging toolkit for virtual functional analyses. Journal of Anatomy 218, 3-15.

Onoda Y, Westoby M, Adler PB, Choong AMF, Clissold, FJ, Cornelisson JHC, Díaz S, Dominy NJ, Elgart A, Enrico L, Fine PVA, Howard JJ, Jalili A, Kitajima K, Kurokawa H, McArthur C, Lucas PW, Markesteijn L, Pérez-Harguindeguy N, Poorter L, Richards L, Santiago LS, Sosinski, EE, Van Bael SA, Warton DI, Wright IJ, Wright SJ, Yamashita N. 2011. Global patterns of leaf mechanical properties. Ecology Letters 14, 301-312.

Rayfield EJ. 2007. Finite element analysis and understanding the biomechanics and evolution of living and fossil organisms. Annual Review of Earth and Planetary Science 35, 541-576.

Scopin AE, Saveljev AP, Suntsova NA, Gnophanxay S, Tikhonov AN, Abramov AV. 2011. Digestive system of the Laotian rock rat Laonastes aenigmamus (Rodentia: Diatomyidae) from the evolutionary viewpoint. Proceedings of the Zoological Institute RAS 315, 3-18.

Simpson GG. 1945. The principles of classification and a classification of mammals. Bulletin of the American Museum of Natural History 85, 1-350.

Tullberg, T. 1899. Über das System der Nagethiere, eine phylogenetische Studie. Nova Acta Regiae Societatis Scientarium Upsaliensis Series 3 18, 1-514.

van Spronsen PH, Weijs WA, Valk J, Prahl-Andersen B, van Ginkel FC. 1989. Comparison of jaw-muscle bite-force cross-sections obtained by means of magnetic resonance imaging and high-resolution CT scanning. Journal of Dental Research 68, 1765-1770.

Weijs WA, Dantuma R. 1975. Electromyography and mechanics of mastication in the albino rat. Journal of Morphology 146, 1-34.

Wilson DE, Reeder DM. 2005. Mammal Species of the World. Baltimore: Johns Hopkins Press. 
390 Wood AE. 1965. Grades and clades among rodents. Evolution 19, 115-130.

391 Wood SA, Strait DS, Dumont ER, Ross CF, Grosse IR. 2011. The effects of modeling simplifications on craniofacial finite element analyses: the alveoli (tooth sockets) and periodontal ligaments. Journal of Biomechanics 44, 1831-1838.

394 Wroe S. 2010. Cranial mechanics of mammalian carnivores: recent advances using a finite element approach. In: Goswami A, Friscia A, eds. Carnivoran Evolution. New Views on Phylogeny, Form and Function. Cambridge: Cambridge University Press, 466-485. 


\section{Figure 1}

Attachment sites and orientations of muscle loads applied to FE model.

Skull of Laonastes aenigmamus shown in $(A)$ lateral and $(B)$ ventral view. Abbreviations: AZM, anterior zygomaticomandibularis; DM, deep masseter; EP, external pterygoid; IOZM, infraorbital part of the zygomaticomandibularis; IOZMa, anterior placement of IOZM origin; IOZMp, posterior placement of IOZM origin; IP, internal pterygoid; MT, main part of termporalis; OT, orbital part of temporalis; PT, posterior part of temporalis; SM, superficial masseter. Posterior zygomaticomandibularis not shown.

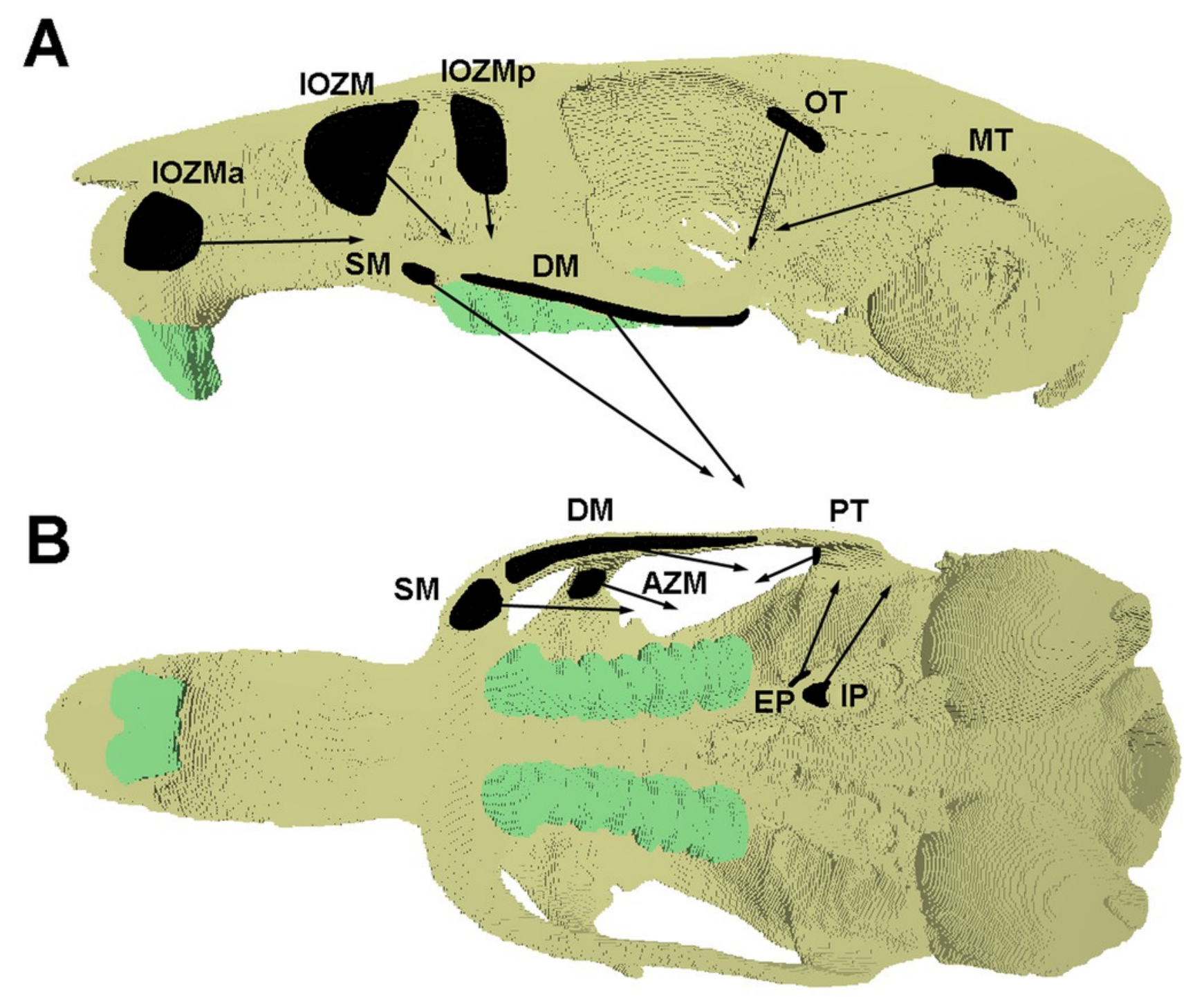




\section{Figure 2}

Landmarks used in GMM analysis of skull deformations.

Reconstruction of skull of Laonastes aenigmamus in (A) dorsal, $(B)$ ventral and $(C)$ left lateral view. 1 , anteriormost point on internasal suture; 2 , midpoint on cranium between anterior roots of zygomatic arch; 3, midpoint between medialmost points on orbital margins; 4 , midpoint on skull roof between zygomatic processes of the squamosal; 5, posteriormost point in dorsal midline; 6 , midpoint between ventral margins of incisal alveoli; 7, midpoint between anteriormost points of premolars; 8 , posteriormost midline point on palate; 9 , midpoint between posterior margins of pterygoid flanges; 10, ventralmost point on margin of foramen magnum; 11, anteriormost point on naso-frontal suture; 12, dorsalmost point on incisal alveolar margin; 13, rostralmost point of infraorbital fossa; 14, midpoint between incisor and premolar on ventrolateral rostral margin; 15, midpoint of dorsal margin of infraorbital fossa; 16, midpoint between 15 and 17; 17, anteriormost attachment of zygomatic arch to rostrum; 18; posteriormost point of infraorbital margin; 19, point on ventrolateral margin of zygomatic arch in same coronal plane as midpoint of $\mathrm{M} 1 ; 20$, apex of tubercle on anterior orbital margin; 21 , dorsalmost point on orbital margin; 22, ventralmost point on orbital margin; 23, midpoint between 21 and 24; 24, posteriormost point on orbital margin. Landmarks 11-24recorded on both sides. 

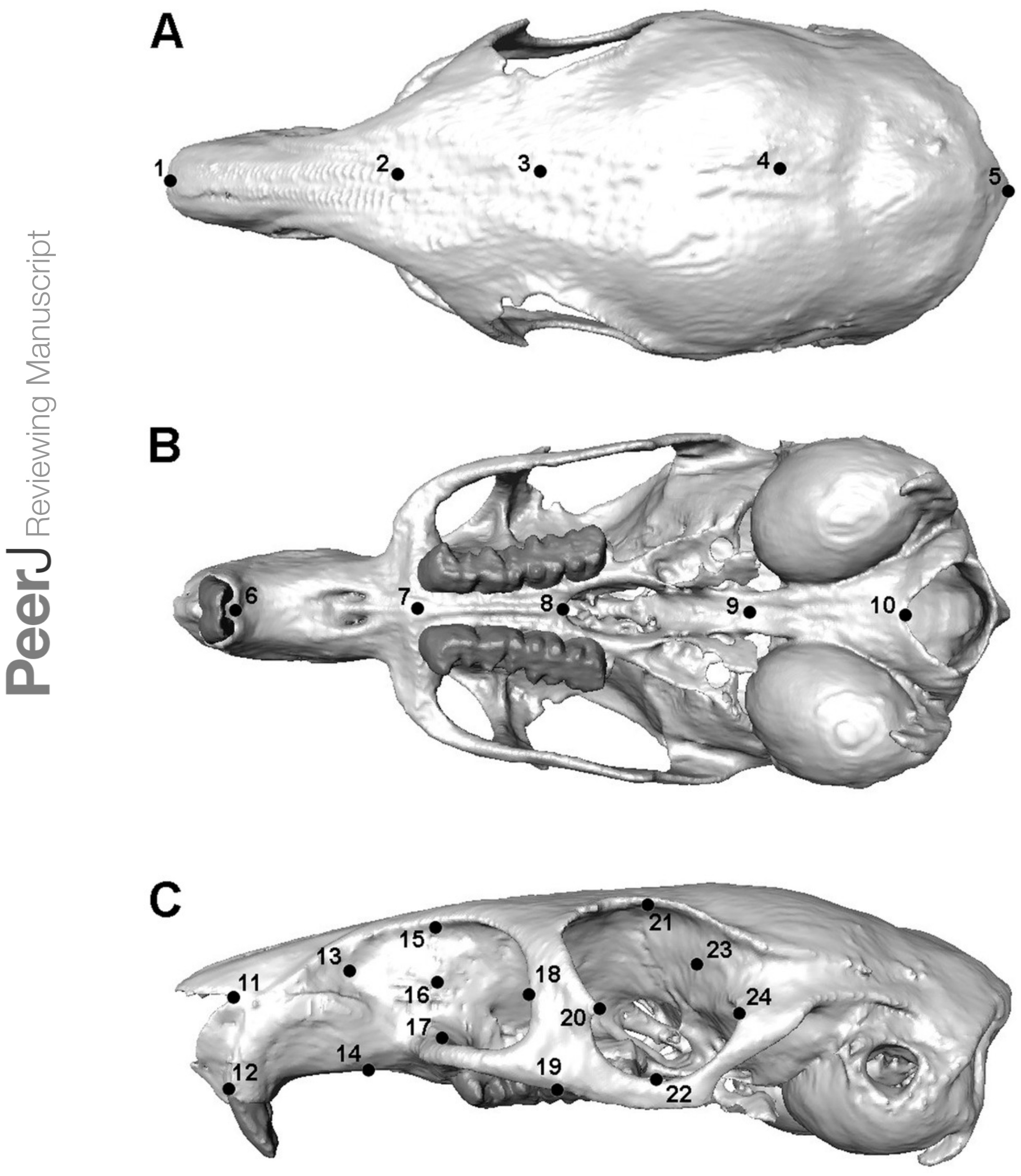


\section{Figure 3}

Predicted distribution of von Mises stresses across the skull of Laonastes aenigmamus.

Arrows indicate the biting tooth. First column, incisor bites; second column, M1 bites; third column, M3 bites. First line, original models; second line, origin of IOZM moved anteriorly to front of rostrum; third line, origin of IOZM moved posteriorly to back of rostrum; fourth line, IOZM muscle force removed and redistributed proportionally between the remaining masticatory muscles.

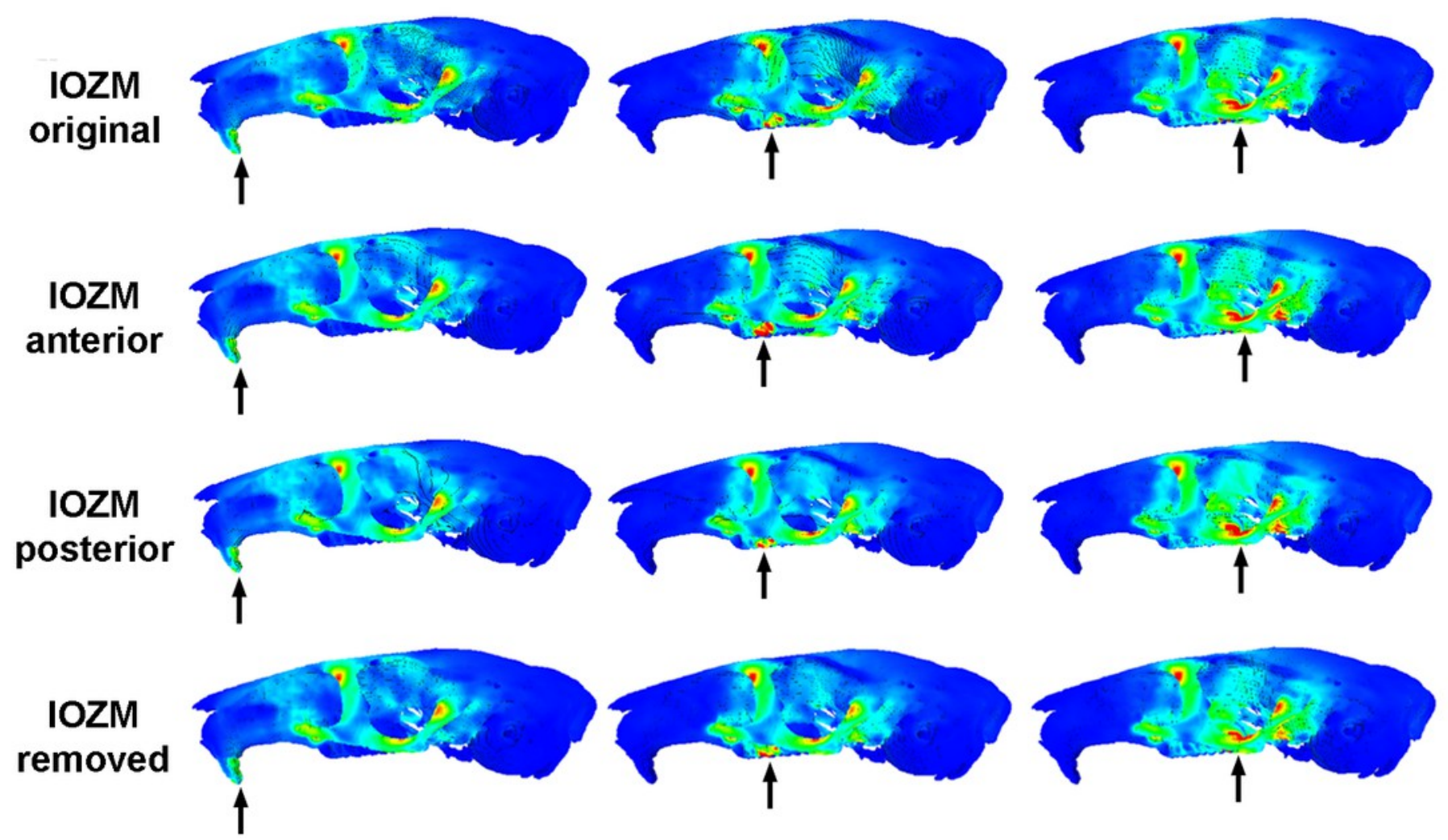




\section{Figure 4}

Mechanical efficiency of biting at each tooth

Predicted from FE models of squirrel, guinea pig, rat and Laotian rock rat skulls. Data for squirrel, guinea pig and rat from Cox et al. (2012). Abbreviations: I, incisor; PM, premolar (absent in rats); M, molar.

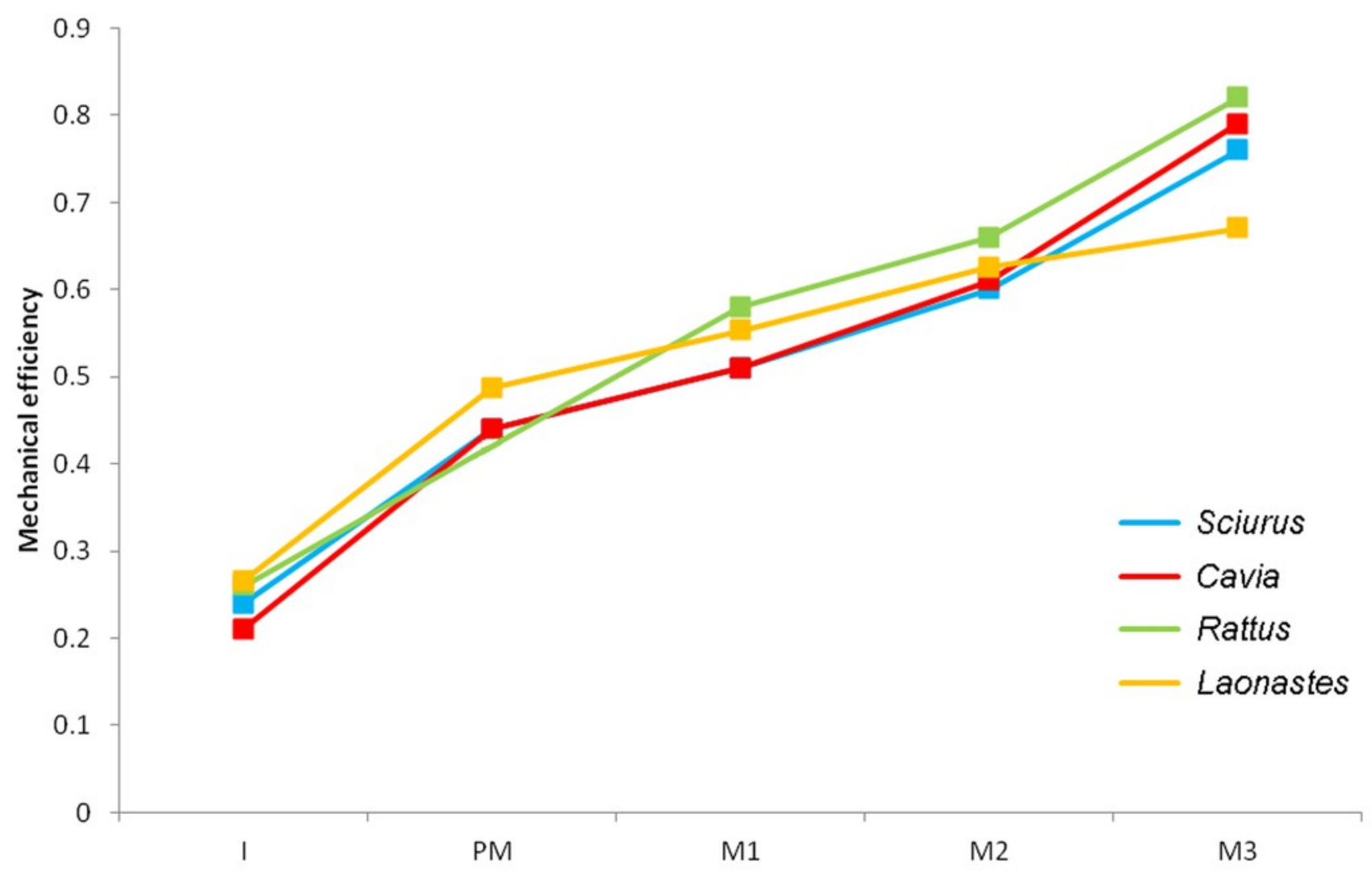




\section{Figure 5}

GMM analysis of cranial deformations in Laonastes aengimamus.

Plot of the first two principal components from a GMM analysis of 24 cranial landmarks. Cranial reconstructions and thin-plate splines indicate shape changes (x 200) along the first and second principal components. PC1 and PC2 not to same scale. Key: star, unloaded model; squares, incisor bites; diamonds, premolar bites; triangles, M1 bites; circles, M2 bites; lines, M3 bites; blue, IOZM in original position; green, IOZM moved anteriorly; red, IOZM moved posteriorly; orange, IOZM force redistributed between other masticatory muscles.
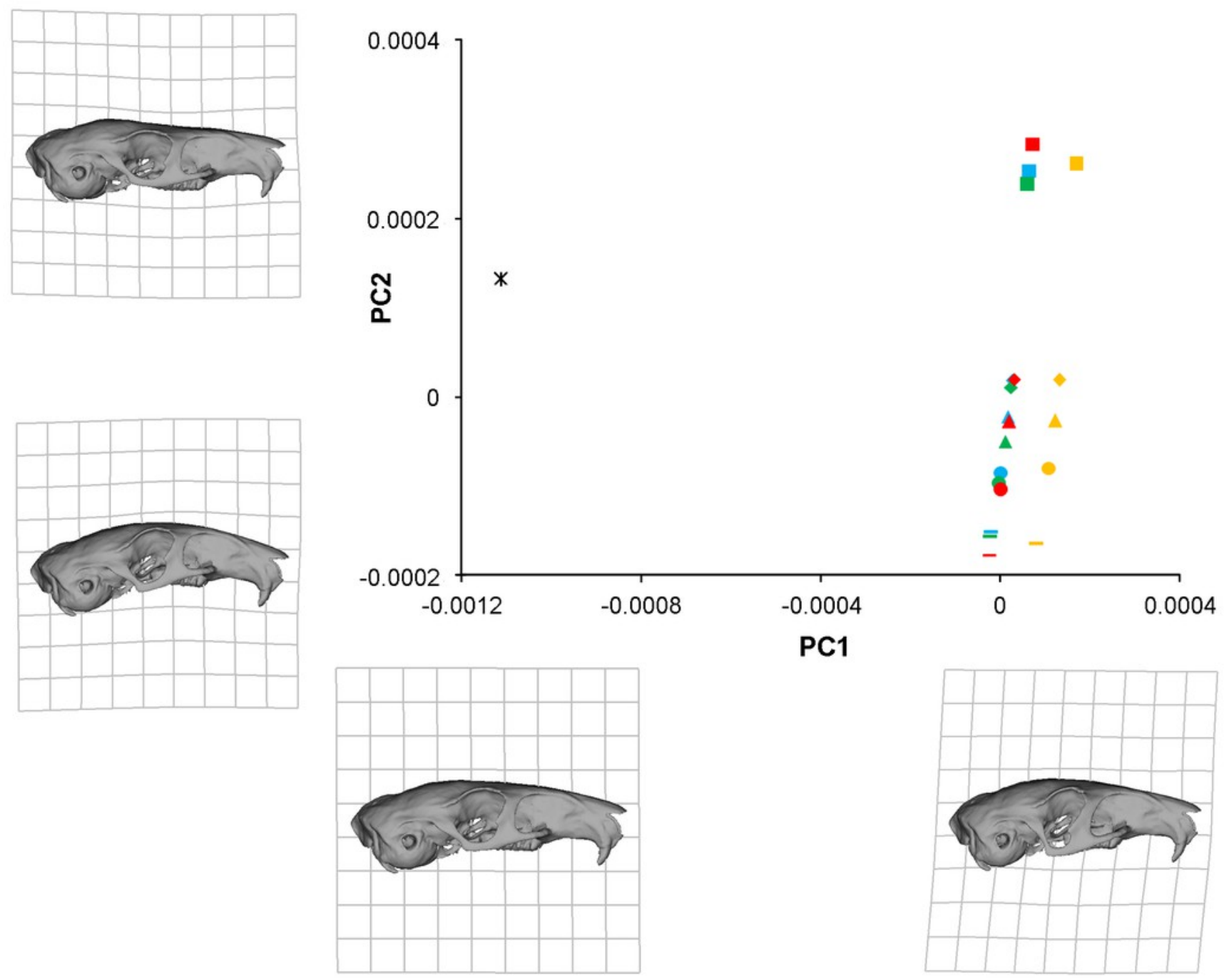


\section{Table 1 (on next page)}

Muscle mass $(\mathrm{g})$, mean fibre length $(\mathrm{mm})$ and PCSA $\left(\mathrm{cm}^{2}\right)$ of masticatory muscles of Laonastes aenigmamus, specimen KY213.

Abbreviations: ZM, zygomaticomandibularis 


\begin{tabular}{|l|c|c|c|}
\hline & Mass (g) & Fibre length (mm) & PCSA (cm $)$ \\
\hline Superficial masseter & 0.348 & 8.73 & 0.376 \\
\hline Deep masseter & 0.235 & 7.71 & 0.287 \\
\hline Anterior ZM & 0.285 & 9.16 & 0.293 \\
\hline Posterior ZM & 0.033 & 3.70 & 0.084 \\
\hline Infraorbital ZM & 0.152 & 9.71 & 0.148 \\
\hline Main temporalis & 0.047 & 8.58 & 0.052 \\
\hline Orbital temporalis & 0.019 & 4.67 & 0.037 \\
\hline Posterior temporalis & 0.017 & 3.70 & 0.042 \\
\hline Internal pterygoid & 0.188 & 6.34 & 0.280 \\
\hline External pterygoid & 0.118 & 4.67 & 0.239 \\
\hline
\end{tabular}




\section{Table 2 (on next page)}

Muscle loads $(\mathrm{N})$ applied to each side of each model in the presence and absence of the IOZM.

Abbreviations: ZM, zygomaticomandibularis 


\begin{tabular}{|l|c|c|}
\hline & With IOZM & Without IOZM \\
\hline Superficial masseter & 11.31 & 12.30 \\
\hline Deep masseter & 8.62 & 9.37 \\
\hline Anterior ZM & 8.80 & 9.57 \\
\hline Posterior ZM & 2.50 & 2.72 \\
\hline Infraorbital ZM & 4.44 & - \\
\hline Main temporalis & 1.56 & 1.70 \\
\hline Orbital temporalis & 1.12 & 1.21 \\
\hline Posterior temporalis & 1.27 & 1.38 \\
\hline Internal pterygoid & 8.40 & 9.13 \\
\hline External pterygoid & 7.15 & 7.78 \\
\hline Total & $\mathbf{5 5 . 1 7}$ & $\mathbf{5 5 . 1 7}$ \\
\hline
\end{tabular}




\section{Table 3 (on next page)}

Mean von Mises stress (MPa) across the skull.

Abbreviations: I, incisor; PM, premolar; M, molar. 


\begin{tabular}{|l|c|c|c|c|}
\hline & $\begin{array}{c}\text { Original } \\
\text { model }\end{array}$ & $\begin{array}{c}\text { IOZM origin } \\
\text { moved anteriorly }\end{array}$ & $\begin{array}{c}\text { IOZM origin } \\
\text { moved } \\
\text { posteriorly }\end{array}$ & $\begin{array}{c}\text { IOZM force } \\
\text { redistributed }\end{array}$ \\
\hline I & 2.31 & 2.27 & 2.32 & 2.34 \\
\hline PM & 2.14 & 2.15 & 2.13 & 2.15 \\
\hline M1 & 2.29 & 2.28 & 2.23 & 2.28 \\
\hline M2 & 2.66 & 2.59 & 2.60 & 2.57 \\
\hline M3 & 3.04 & 2.86 & 2.99 & 2.95 \\
\hline
\end{tabular}




\section{Table 4 (on next page)}

Predicted bite forces (N) across the skull.

Abbreviations: I, incisor; PM, premolar; M, molar. 


\begin{tabular}{|l|c|c|c|c|}
\hline & $\begin{array}{c}\text { Original } \\
\text { model }\end{array}$ & $\begin{array}{c}\text { IOZM origin } \\
\text { moved anteriorly }\end{array}$ & $\begin{array}{c}\text { IOZM origin } \\
\text { moved } \\
\text { posteriorly }\end{array}$ & $\begin{array}{c}\text { IOZM force } \\
\text { redistributed }\end{array}$ \\
\hline I & 29.27 & 25.74 & 29.05 & 26.61 \\
\hline PM & 53.74 & 46.93 & 53.72 & 48.80 \\
\hline M1 & 61.00 & 54.93 & 61.70 & 55.78 \\
\hline M2 & 68.97 & 61.92 & 70.32 & 62.05 \\
\hline M3 & 73.93 & 65.35 & 74.38 & 66.61 \\
\hline
\end{tabular}

